\title{
Improving electrochemical performance of tin-based anodes formed via oblique angle deposition method
}

\author{
B DENIZ POLAT and OZGUL KELES* \\ Department of Metallurgical and Materials Engineering, Istanbul Technical University, Maslak, Istanbul 34469, Turkey
}

MS received 17 December 2013

\begin{abstract}
An oblique angle electron beam co-deposition technique was used to fabricate nanostructured Sn-based thin films: $\mathrm{Sn}, \mathrm{Cu}-\mathrm{Sn}$ and $\mathrm{Cu}-\mathrm{Sn}-\mathrm{C}$. The morphological and structural properties of the films were observed via scanning electron microscopy (SEM) and thin film X-ray diffraction (XRD) methods. The electrochemical (CV and EIS) and the galvanostatic test results demonstrated that the addition of $\mathrm{Cu}$ with or without $\mathrm{C}$ affected the electrochemical performance of the thin film positively since $\mathrm{Cu}$ and $\mathrm{C}$ improved both the mechanical and the electrical properties of the nanostructured $\mathrm{Sn}$ thin film electrode. The high cycleability and capacity retention were achieved when the nanostructured $\mathrm{Cu}-\mathrm{Sn}-\mathrm{C}$ thin film was used as an anode material since $\mathrm{C}$ increased the mechanical tolerance of the thin film to the volume expansion due to its grain refiner effect. $\mathrm{Cu}$ not only improved the electrical conductivity and the adhesion of the film to substrate but also the mechanical tolerance of the film with its ductile property.
\end{abstract}

Keywords. Thin film; oblique angle deposition; lithium ion batteries; anode.

\section{Introduction}

In recent times, researchers have been focussing on developing new electrode materials for lithium ion batteries, which have a higher reversible capacity than those of the carbonbased materials. For this purpose, different metals, alloys and intermetallics are studied as negative electrodes (Besenhard et al 1997; Wachtler et al 2001; Lindsay et al 2003; Lee 2007; Kamali and Fray 2011). Among alternatives, tin (Sn) is attractive because it has a higher theoretical retention capacity (994 $\mathrm{mAh}^{-1}$ ) than graphite (372 $\mathrm{mAh} \mathrm{g}^{-1}$ ) (Besenhard et al 1997; Wachtler et al 2001). However, the use of pure $\mathrm{Sn}$ as an anode material is restricted because of the high volume change during the cycling test, which in turn causes a loss of the electrical contact among the particles and between the current collector with the thin film, which eventually leads to failure (Kamali and Fray 2011).

To reduce such restrictions, $\mathrm{M}_{x} \mathrm{Sn}_{y}$ intermetallic binary systems (where $\mathrm{M}$ is an inactive metal, such as $\mathrm{Cu}, \mathrm{Ni}$, $\mathrm{Fe}, \mathrm{Co}, \mathrm{Sb}, \mathrm{Ag}$ ) are used as an anode (Lindsay et al 2003; Kawakami and Asao 2005; Mizutani and Inoue 2005; Chen et al 2008; Kamali and Fray 2011). Herein, copper (Cu) is preferred mostly due to its high electrical conductivity and its high ductility. These properties are expected to increase the conductivity and the mechanical tolerance of the thin film against the volumetric changes that occur during cycling (Kepler et al 1999; Belt et al 2003; Kawakami and Asao 2005; Mizutani and Inoue 2005; Zhang et al 2011). Cu-Sn phase diagram has various $\mathrm{Cu}_{x} \mathrm{Sn}_{y}$ intermetallics: $\mathrm{Cu}_{6} \mathrm{Sn}_{5}$ is

*Author for correspondence (ozgulkeles@itu.edu.tr) remarkable due to its easy structural decomposition in a conductive $\mathrm{Cu}$ matrix (1) and (2) during the lithiation reaction (Kepler et al 1999; Jung and Lee 2011). In previous studies, it is shown that the anode made of $\mathrm{Cu}_{6} \mathrm{Sn}_{5}$ particles has a longer cycle life compared to that of the pure Sn anode because during lithiation, lithium (Li) first reacts to form $\mathrm{Li}_{2} \mathrm{Cu}_{6} \mathrm{Sn}_{5}$ (1), and then with further $\mathrm{Li}$ addition $\mathrm{Li}_{2} \mathrm{Cu}_{6} \mathrm{Sn}_{5}$ decomposes into Li-Sn alloys (2) surrounded by $\mathrm{Cu}$ matrix (Besenhard et al 1986; Kepler et al 1999; Thackeray et al 2005).

$$
\begin{aligned}
& 10 \mathrm{Li}+5 \mathrm{Cu}_{6} \mathrm{Sn}_{5} \rightleftharpoons 5 \mathrm{Li}_{2} \mathrm{Cu}_{6} \mathrm{Sn}_{5}, \\
& 20 \mathrm{Li}+\mathrm{Li}_{2} \mathrm{Cu}_{6} \mathrm{Sn}_{5} \rightleftharpoons 5 \mathrm{Li}_{4 \cdot 4} \mathrm{Sn}+6 \mathrm{Cu} .
\end{aligned}
$$

Nevertheless, such efforts are still limited in sustaining a high Columbic efficiency because the ductility induced by the limited $\mathrm{Cu}$ atoms is not enough to tolerate the volume change that occurs during the charge/discharge reactions, which deteriorates the stability of the interface between the electrode and the electrolyte. Accordingly, it is necessary to find out a remarkable matrix to minimize the morphological changes and to prevent the loss of electronic conductivity during the lithiation/delithiation reactions. Within this concept, Kawakami and Asao (2005) proposed using an amorphous electrode material consisting of SnAX where A is a transition metal and $\mathrm{X}$ is at least one of the elements: $\mathrm{O}, \mathrm{F}, \mathrm{N}$, $\mathrm{Mg}, \mathrm{Ba}, \mathrm{Sr}, \mathrm{Ca}, \mathrm{La}, \mathrm{Ce}, \mathrm{Si}, \mathrm{Ge}, \mathrm{C}, \mathrm{P}, \mathrm{B}, \mathrm{Pb}, \mathrm{Bi}, \mathrm{Sb}, \mathrm{Al}, \mathrm{Ga}, \mathrm{In}$, Tl, Zn, Be, Pr, Nd, Sm, Eu, Gd, Tb, Dy, Ho, Er, Tm, Yb, Lu, As, Se, Te, Li, and S. Moreover, Mizutani and Inoue (2005) anticipated this idea by using SnMX systems where $\mathrm{M}$ is one of the elements: $\mathrm{Ni}, \mathrm{Cu}, \mathrm{Fe}, \mathrm{Co}, \mathrm{Mn}, \mathrm{Zn}$, In or $\mathrm{Ag}$; and $\mathrm{X}$ is one of the elements: $\mathrm{B}, \mathrm{C}, \mathrm{Al}, \mathrm{Si}, \mathrm{P}$, or $\mathrm{S}$. Among these 
options, Sn-Co-C-based material, which was commercialized by Sony in 2005, appears to be very attractive (Zhang et al 2011). However, since Co is very expensive and toxic, the need for finding alternative anode materials is still under discussion.

In this study, bare $\mathrm{Sn}$ and composite $\mathrm{Cu}-\mathrm{Sn}$ and $\mathrm{Cu}-\mathrm{Sn}-$ $\mathrm{C}$ nanostructured thin film anodes are deposited on $\mathrm{Cu}$ discs by glancing angle electron (GLAD) beam evaporation process. GLAD process is chosen particularly because there is no risk of hazardous handling of flammable, explosive or cancerogenous metal nanoparticles; and no need of binder or conductive additives to get a nanosized electrode with nanoporosities. The porosities in the films are expected to significantly improve the performance of the rechargeable batteries since they would provide easy access of the electrolyte to the entire electrode surface. Moreover, it is believed that with the lack of binder, the electrical resistance would be also very low in these films (Kepler et al 1999; Belt et al 2003; Jung and Lee 2011).

In this study, for the first time in the literature, a nanostructured $\mathrm{Cu}-\mathrm{Sn}-\mathrm{C}$ thin film is produced via the GLAD method, where the evaporation of carbon is achieved in a controlled manner. In this paper, the possible use of the $\mathrm{Cu}-\mathrm{Sn}-\mathrm{C}$ thin film as an anode material is investigated by comparing its electrochemical performance to that of the nanostructured $\mathrm{Sn}$ and the nanostructured $\mathrm{CuSn}$ thin films. The results clearly demonstrate the positive effects of the porous morphology and the presence of $\mathrm{Cu}$ and $\mathrm{C}$ in the thin film on the electrochemical performances of the electrodes, in order to fabricate a high-performance Sn-based anode for lithium ion batteries.

\section{Experimental}

Three Sn containing thin films (pure $\mathrm{Sn}, \mathrm{Cu}-\mathrm{Sn}$ and $\mathrm{Cu}-\mathrm{Sn}-\mathrm{C})$ were fabricated on $\mathrm{Cu}$ discs $(15.5 \mathrm{~mm}$ diameter, $1.5 \mathrm{~mm}$ thickness) by using the glancing angle electron beam co-deposition technique. During the deposition process, the base vacuum in the chamber was around $10^{-7}$ mTorr. Two

Table 1. Batch compositions in each crucible prior to deposition.

\begin{tabular}{|c|c|c|}
\hline Coatings & Crucible 1 & Crucible 2 \\
\hline Sn thin film & Pure Sn pellets & - \\
\hline $\mathrm{Cu}-\mathrm{Sn}$ thin film & $\begin{array}{l}\text { Mixture of } \mathrm{Cu}-\mathrm{Sn} \\
\text { pellets }(2 / 3 \mathrm{wt} \%)\end{array}$ & - \\
\hline $\mathrm{Cu}-\mathrm{Sn}-\mathrm{C}$ thin film & $\begin{array}{l}\text { Mixture of } \mathrm{Cu}-\mathrm{Sn} \\
\text { pellets }(2 / 3 \mathrm{wt} \%)\end{array}$ & Graphite \\
\hline
\end{tabular}

graphite crucibles were used. Batch compositions in the crucibles for each deposition are given in table 1 .

In order to produce the nanostructured $\mathrm{Sn}, \mathrm{Cu}-\mathrm{Sn}$ and $\mathrm{Cu}-$ $\mathrm{Sn}-\mathrm{C}$ thin films, first $\mathrm{Sn}$ (for bare $\mathrm{Sn}$ thin film) or $\mathrm{Cu}-\mathrm{Sn}$ (for $\mathrm{Cu}-\mathrm{Sn}$ or $\mathrm{Cu}-\mathrm{Sn}-\mathrm{C}$ thin films) were deposited with an incident flux angle of $0^{\circ}$, because it was believed that the presence of this non-porous (flat) thin film would increase the electrical contact of the nanostructured thin film to the substrate. Then, a subsequent co-deposition of $\mathrm{Sn}, \mathrm{Cu}-\mathrm{Sn}$, $\mathrm{Cu}-\mathrm{Sn}-\mathrm{C}$ thin films were achieved with an angle of $80^{\circ}$ (vs the target's surface normal) on the non-porous layer to form the nanostructured $\mathrm{Sn}, \mathrm{Cu}-\mathrm{Sn}$ and $\mathrm{Cu}-\mathrm{Sn}-\mathrm{C}$ thin films, respectively. The compositions of the film were determined by energy-dispersive X-ray spectroscopy (EDX) analysis and are given in table 2 .

The surface morphology of the thin films prior and after the galvanostatic tests were analyzed by utilizing a field-emission scanning electron microscopy (FE-SEM, JEOL JSM 7000F). The samples were washed with dimethyl carbonate (DMC) before the analysis. The phases present in the pristine films were determined by using Philips PW3710 System (with $\mathrm{CuK} \alpha$ at $40 \mathrm{kV}$ and $30 \mathrm{~mA}$ ). The X-ray data were collected in the $2 \theta$ range of $20-90^{\circ}$ in steps of $0.05^{\circ}$.

Moreover CR2032 coin cells were fabricated to test the electrochemical properties of the electrodes. The cells were assembled in an Argon filled glove-box (MBRAUN, Labmaster). The testing cells were based on the following sequence: (i) a working electrode, (ii) a $1 \mathrm{M} \mathrm{LiPF}_{6}$ in the ethylene carbonate-dimethyl carbonate, EC:DMC 1:1 (Merck Battery Grade) electrolyte solution, (iii) separator (Celgrad 2400) and (iv) a lithium metal foil as a counter electrode.

The cells were tested at room temperature between $5 \mathrm{mV}$ and $2.5 \mathrm{~V} \mathrm{vs} \mathrm{Li} / \mathrm{Li}^{+}$with a rate of $50 \mathrm{~mA} \mathrm{~g}{ }^{-1}$. The cyclic voltammetry $(\mathrm{CV})$ was performed in the potential range of $5 \mathrm{mV}-2.5 \mathrm{~V}$ vs Li/ $/ \mathrm{Li}^{+}$at a scan rate $0.03 \mathrm{mV} \mathrm{s}^{-1}$. The impedance spectra after the first and the third cycles were also recorded in a frequency range of $1000-0 \cdot 01 \mathrm{~Hz}$ with an amplitude of $5 \mathrm{mV}$.

\section{Results and discussion}

\subsection{Structural and morphological characterization}

By placing the $\mathrm{Cu}$ substrate above a material vapor source at an oblique angle, a nanostructured thin film is fabricated. These nanostructures are oriented towards the vapor source because of the self-shadowing effect and they are

Table 2. Results of EDS analyses on $\mathrm{Cu}-\mathrm{Sn}$ and $\mathrm{Cu}-\mathrm{Sn}-\mathrm{C}$ thin films.

\begin{tabular}{|c|c|c|c|c|c|c|}
\hline \multirow[b]{2}{*}{ Coatings } & \multicolumn{2}{|c|}{$\mathrm{Cu}$} & \multicolumn{2}{|c|}{$\mathrm{Sn}$} & \multicolumn{2}{|c|}{$\mathrm{C}$} \\
\hline & $(\mathrm{wt} \%)$ & $(\mathrm{at} \%)$ & $(w t \%)$ & $(\mathrm{at} \%)$ & $(\mathrm{wt} \%)$ & (at $\%)$ \\
\hline $\mathrm{Cu}-\mathrm{Sn}$ & 53.07 & $67 \cdot 87$ & $46 \cdot 93$ & $32 \cdot 13$ & 0 & \\
\hline $\mathrm{Cu}-\mathrm{Sn}-\mathrm{C}$ & $32 \cdot 19$ & $29 \cdot 47$ & $59 \cdot 24$ & $29 \cdot 03$ & 8.57 & 41.50 \\
\hline
\end{tabular}


homogeneously distributed in the thin film because of the limited surface diffusion ability of ad-atoms (Patzig et al 2010). Figure 1(a)-(f) reveals the surface and the cross sectional views of the nanostructured $\mathrm{Sn}, \mathrm{Cu}-\mathrm{Sn}$ and $\mathrm{Cu}-\mathrm{Sn}-\mathrm{C}$ thin films.

The pure nanostructured $\mathrm{Sn}$ electrode has a remarkable pillar-like structure and the thin film is fairly inhomogeneous in sizes (figure 1a). Its cross sectional view demonstrates clearly that the pillars are not homogeneously deposited on $\mathrm{Cu}$ substrate and the thickness is around $150 \pm 50 \mathrm{~nm}$ (figure 1d). On the other hand, the electrode made of $\mathrm{Cu}-\mathrm{Sn}$ nanostructured composite thin film has well-aligned composite nanorod arrays where the nanorods' diameters $(<100 \mathrm{~nm})$ are very homogeneous (figure $1 \mathrm{~b})$. The cross sectional view displays that the resulting film thickness is around $230 \pm 20 \mathrm{~nm}$ and the interstitial spaces among the nanorods represent homogeneously distributed nanoporosities (figure 1e) in the thin film. For the electrode made of
$\mathrm{Cu}-\mathrm{Sn}-\mathrm{C}$ thin film in figure $1(\mathrm{f})$, no remarkable nanocolumnar structure is detected, but the surface view exhibits the presence of the homogeneously distributed nanosized porosities in the nanostructured thin film.

The comparison between $\mathrm{Cu}-\mathrm{Sn}$ containing thin films' XRD data with that of Sn displays that an additional amount of $\mathrm{Cu}$ enhances the intermetallic formation. Figure 2 displays the presence of $\mathrm{Cu}$-rich $\mathrm{Cu}_{6} \mathrm{Sn}_{5}\left(\mathrm{Cu}_{6.26} \mathrm{Sn}_{5}\right)$ crystallites instead of Sn nanocrystallites in the CuSn thin film. The high $\mathrm{Cu}$ content in the nanocolumnar structured $\mathrm{Cu}-\mathrm{Sn}$ thin film is also justified by EDS analysis (table 2).

The EDS analysis shows that the thin films have different compositions than the source composition. The difference between the source and the thin film composition can be explained as being an outcome of the evaporation point differences of the metals at constant pressure and the nature of the GLAD method. Because in the GLAD method, the deposition rate not only has a vertical component (with respect
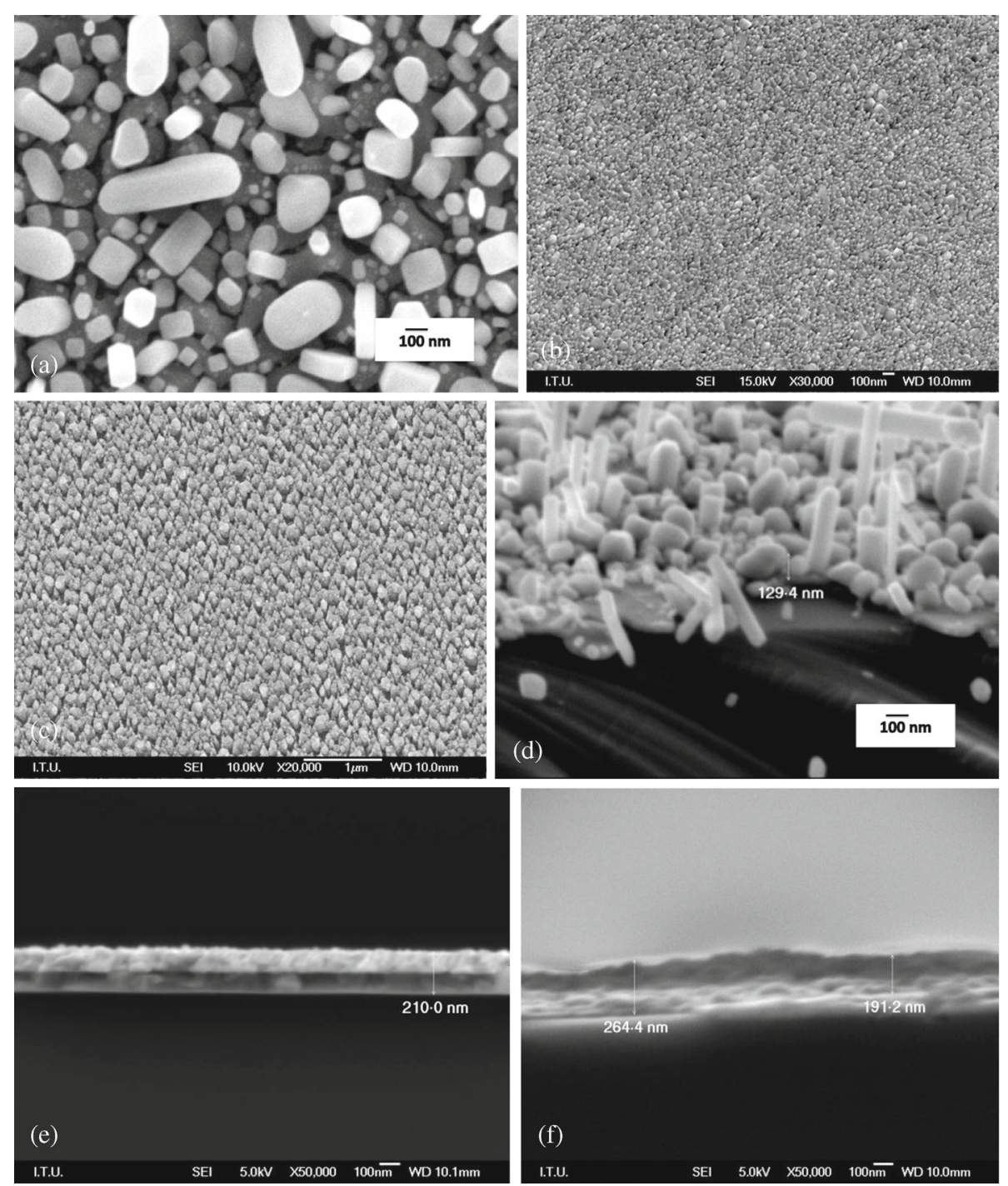

Figure 1. SEM surface views of nanostructured (a) bare $\mathrm{Sn}$, (b) $\mathrm{Cu}-\mathrm{Sn},(\mathbf{c}) \mathrm{Cu}-\mathrm{Sn}-\mathrm{C}$ thin films; SEM cross sectional views of nanostructured (d) bare $\mathrm{Sn}$, (e) $\mathrm{CuSn}$ and (f) $\mathrm{Cu}-\mathrm{Sn}-\mathrm{C}$ thin films. 


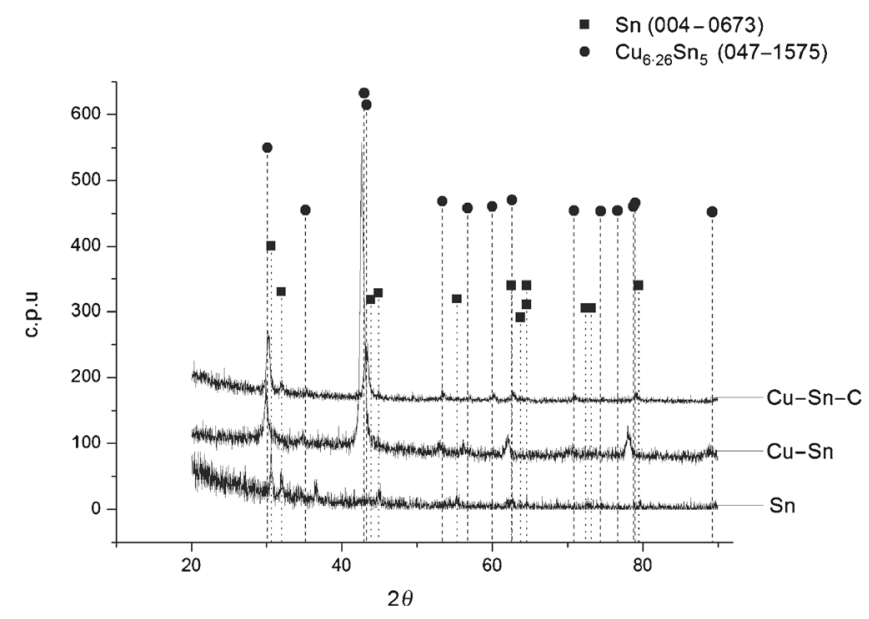

Figure 2. XRD analyses results of nanostructured bare $\mathrm{Sn}$, $\mathrm{Cu}-\mathrm{Sn}$ and $\mathrm{Cu}-\mathrm{Sn}-\mathrm{C}$ thin films.

to the substrate surface), but also has a lateral component, which in turn forms thin films with different compositions and thicknesses (Derrien et al 2007). Moreover, figure 2 demonstrates the small peak shift in the $\mathrm{Cu}-\mathrm{Sn}$ film, which may be explained by the internal stress of the thin film due to the existence of the excessive amount of $\mathrm{Cu}$ atoms in the $\mathrm{Cu}_{6} \mathrm{Sn}_{5}$ crystal. However, the XRD data of $\mathrm{Cu}-\mathrm{Sn}-\mathrm{C}$ containing thin film shows no peak shift because of the presence of $\mathrm{C}$ in the thin film, which results in a reduction of the grain size of forming the nanostructured thin film electrode. The fact that there is a broadening in the Sn peak at $30.645^{\circ}$ and a decrease in its intensity also supports the grain refiner effect of the carbon atom. Moreover, the absence of the characteristic peak at $89.7^{\circ}$ for $\mathrm{Cu}_{6.26} \mathrm{Sn}_{5}$ justifies that an excessive $\mathrm{Cu}$ is not present in the crystal of $\mathrm{Cu}_{6} \mathrm{Sn}_{5}$ for $\mathrm{Cu}-\mathrm{Sn}-\mathrm{C}$ thin film. When the XRD data of the $\mathrm{Cu}-\mathrm{Sn}-\mathrm{C}$ is observed in detail, no peak related to the presence of carbon is noted, which could be related to the amorphous phase of carbon as revealed by the presence of a bump at low diffraction angles.

\subsection{Electrochemical characterization}

The cyclic voltammograms $(\mathrm{CV})$ of the pristines $\mathrm{Sn}, \mathrm{Cu}-\mathrm{Sn}$ and $\mathrm{Cu}-\mathrm{Sn}-\mathrm{C}$ thin films are shown in figure $3(\mathrm{a})-(\mathrm{c})$. The reduction peaks related to the formation of $\mathrm{Li}-\mathrm{Sn}$ materials, and the anodic peaks corresponding to $\mathrm{Li}$ de-alloying reactions are detected for all thin films. For the nanostructured $\mathrm{Sn}$ thin film, one irreversible and two reversible reduction peaks are observed around $0.7,0.5$ and $0.3 \mathrm{~V} \mathrm{vs} \mathrm{Li} / \mathrm{Li}^{+}$, which are related to the electrolyte reduction (to form SEI), and $\mathrm{Li}-\mathrm{Sn}$ alloys (with Li-deficient and $\mathrm{Li}$-rich phases) formation, respectively (Jung and Lee 2011). The anodic peaks detected in figure 1(a) show that the first discharge reaction is partially reversible, resulting in the recovery of Sn partially from the lithiated products. For the $\mathrm{Cu}-\mathrm{Sn}$ thin film, the reduction peaks around 0.3 and $0.1 \mathrm{~V}$ indicate the formation of $\mathrm{Li}-\mathrm{Sn}$ (Li-rich) alloys formation. The anodic peaks noted around 0.5 and $0.7 \mathrm{~V}$ demonstrate that the SEI layer might

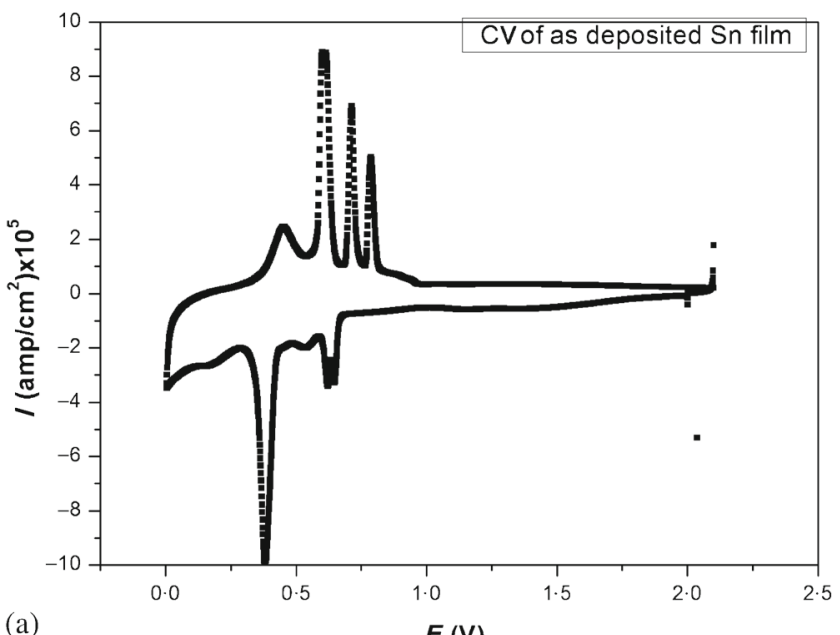

(a)

$E(\mathrm{~V})$
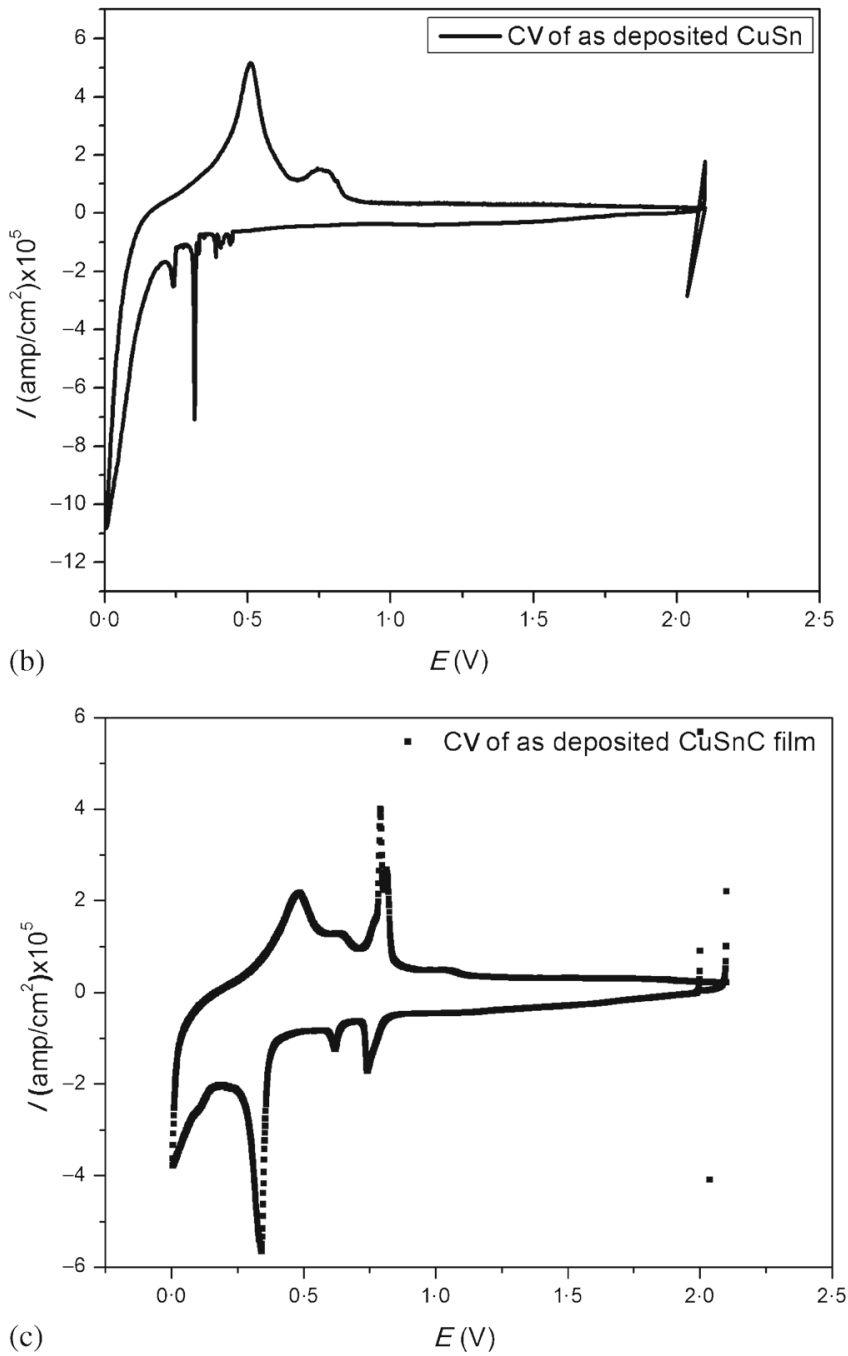

Figure 3. CV analyses of the as deposited nanostructured (a) bare $\mathrm{Sn},(\mathbf{b}) \mathrm{Cu}-\mathrm{Sn}$ and (c) $\mathrm{Cu}-\mathrm{Sn}-\mathrm{C}$ thin films.

form during the reduction process, since the first discharge reaction is not fully reversible. The first cycle $\mathrm{CV}$ data of the nanostructured $\mathrm{Cu}-\mathrm{Sn}-\mathrm{C}$ thin film justifies the formation of the SEI on the electrode surface (figure $3 \mathrm{c}$ ) with a reduction 
peak observed at $0.8 \mathrm{~V}$. The other cathodic $(\sim 0.6, \sim 0.3$ and $\sim 0.0 \mathrm{~V})$ and the anodic peaks $(\sim 0.5, \sim 0.6 \mathrm{~V})$ show the lithiation/delithiation of the $\mathrm{Cu}-\mathrm{Sn}-\mathrm{C}$ electrode according to (1) and (2) (Shin and Liu 2005).

When the CV data of all the nanostructured thin films are compared, it is possible to discuss the effect of $\mathrm{Cu}$ and/or $\mathrm{C}$ on the thin film's electrochemical performance: $\mathrm{Cu}$ has no effect on the peak positions, which justifies that it is inactive when reacting with $\mathrm{Li}$; and $\mathrm{C}$ enhances the activity of $\mathrm{Li}^{+}$since the oxidation and reduction peak intensities are much higher than those of the nanostructured $\mathrm{Sn}$ and $\mathrm{CuSn}$ thin films. Moreover, it seems highly possible to have the SEI formation on the three electrodes' surfaces after the first discharge reaction; because the first lithiation/delithiation reactions have a very high irreversibility.

The complex impedance spectroscopic analysis of the three nanostructured Sn-based thin films after the first and third discharge reactions display the presence of a semicircle at high frequency region, which represents the lithium ion interfacial transfer resistance, and a line having a slope of $45^{\circ}$ angle at low frequency region shows the existence of solid-state diffusion of $\mathrm{Li}^{+}$into the bulk material. Figure 4(a) demonstrates that the nanostructured Sn thin film has two semicircles on the EIS data after the first cycle, which proves that the nanostructured film has multiple interfaces with the electrolyte. After the first cycle, the semicircles gather together to form one circle at the high frequency region and the charge-transfer resistance noted after the third cycle decreases compared to that of the first cycle. This change in impedance could be explained considering the pulverization of the thin film due to high volume changes which in turn distort the film morphology (the pillar morphology is lost, leading to small size particles containing thin film) and the interfaces between the thin film and the electrolyte are settled together eventually. This increase in nanostructured Sn thin film's surface area during cycling affects the detected amount of the current in the impedance. This rise in the current recovered from the electrode could explain the decrease in the impedance of the cells after the 3 rd cycle. On the other hand, the impedance data of the nanostructured $\mathrm{Cu}$ $\mathrm{Sn}$ thin film reveals that an additional semi-circle is formed on the EIS data of the 3rd cycle, where the real impedance value between the current collector and the thin film also decreases. This behavior proves that a partial delamination of the $\mathrm{Cu}-\mathrm{Sn}$ nanorods containing thin film occurs after three cycles, due to the volumetric change. Besides, figure 5(a) shows that even the volume of the $\mathrm{Cu}-\mathrm{Sn}$ thin film increases during lithiation, the film does not delaminate entirely thanks to the improved adhesion (due to the presence of $\mathrm{Cu}$ ) and the homogeneously distributed porosities in the composite thin film. When the EIS data (both the as-deposited and after the 3 rd cycle) of the nanostructured $\mathrm{Cu}-\mathrm{Sn}-\mathrm{C}$ thin film are observed in detail, a decrease in the internal resistance is detected, whereas the real impedance at the interface remains slightly constant. Previous work shows experimentally that $\mathrm{C}$ is generally present in the SEI film that forms on the electrode after the first discharge reaction and remains mostly
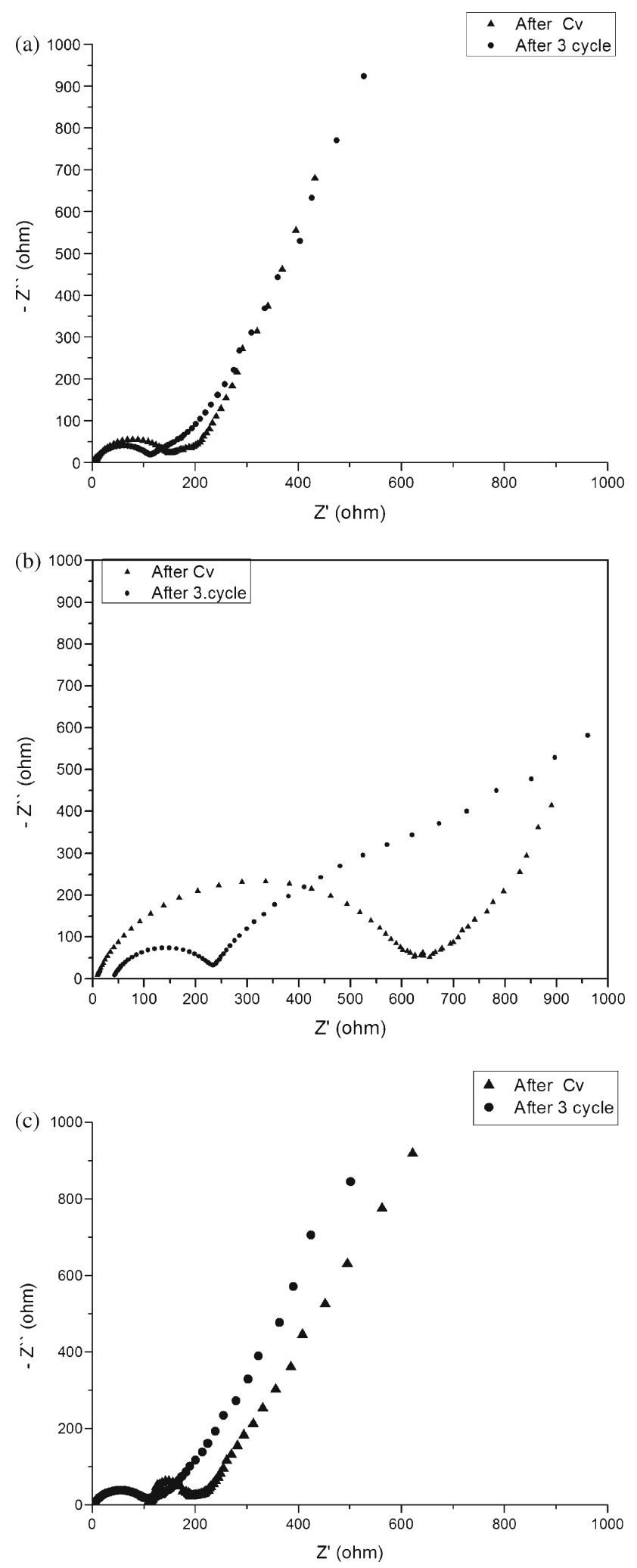

Figure 4. EIS spectra of the as deposited nanostructured (a) bare $\mathrm{Sn},(\mathbf{b}) \mathrm{Cu}-\mathrm{Sn}$ and (c) $\mathrm{Cu}-\mathrm{Sn}-\mathrm{C}$ thin films.

on the surface during the cycling test (Wang et al 2006). Thus, the expected presence of $\mathrm{C}$ in the SEI covering the entire electrode surface could work as binder in the thin film, 

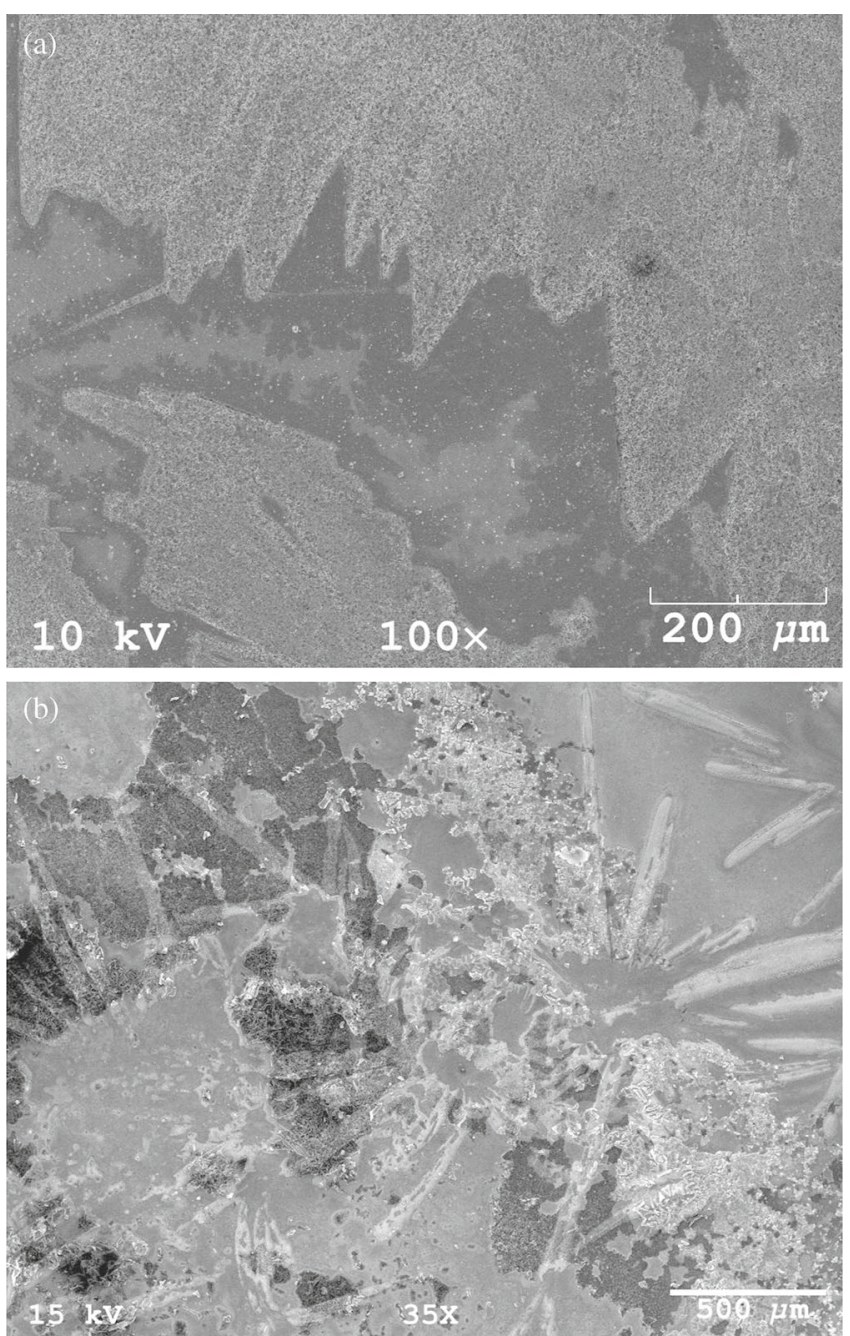

Figure 5. SEM images of (a) the $\mathrm{Cu}-\mathrm{Sn}$ and (b) $\mathrm{Cu}-\mathrm{Sn}-\mathrm{C}$ thin films after 80th cycles.

which decreases the internal resistance of the film after the 3rd cycle. The SEM surface view of the $\mathrm{Cu}-\mathrm{Sn}-\mathrm{C}$ thin film after 80 cycles justifies the partial delamination in the thin film and the pulverization occurs on the remaining part of the electrode (see figure $5 b$ ).

In figure 6(a)-(c), the galvanic charge-discharge test results of the nanostructured $\mathrm{Sn}, \mathrm{Cu}-\mathrm{Sn}$ and $\mathrm{Cu}-\mathrm{Sn}-\mathrm{C}$ thin film anodes are given. The nanostructured Sn film demonstrates the first discharge capacity around $980 \mathrm{mAh} \mathrm{g}^{-1}$, which is almost equal to the theoretical capacity of $\mathrm{Sn}$ (figure 6a). The capacity diminishes gradually in the following 20 cycles. Once the capacity is $450 \mathrm{mAh} \mathrm{g}^{-1}$, a steady state regime is started and reined up to 50th cycles (figure 6a). This gradual decline in the capacity can be explained considering the pulverization of the inhomogenously distributed pillar like Sn particles during lithiation/delithiation reactions. The Columbic efficiency of the anode is around $90 \%$ after the first cycle, which shows that the interaction of the thin film with the electrolyte is not stable under the testing conditions and a continuous loss of $\mathrm{Li}^{+}$ present in the cell during cycling.
The capacity values in the graphs of $\mathrm{Cu}-\mathrm{Sn}$ and $\mathrm{Cu}-\mathrm{Sn}-\mathrm{C}$ thin films are calculated based on the active material present in the thin films. Considering the theoretical capacity of Sn and its composition (table 2); the theoretical capacity of the $\mathrm{Cu}-\mathrm{Sn}$ thin film is found as $465 \mathrm{mAh} \mathrm{g}^{-1}(991 \times 0.4693=$ $465)$. This value is lower than the initial discharge capacity of the sample $\left(800 \mathrm{mAh} \mathrm{g}^{-1}\right)$. Chiu et al explain this fact by the formation of the SEI, which is formed once the active elements react with $\mathrm{Li}^{+}$from the electrolyte (Thackeray et al 2005). When figure 6(b) is analyzed in detail it is seen that the $\mathrm{Cu}-\mathrm{Sn}$ composite thin film having homogeneously distributed nanorods array demonstrates a decrease in the capacity that occurs at the very beginning of the cycling test (in the first 3 cycles, Coulombic efficiency around 60\%) and once the capacity goes down to $300 \mathrm{mAh} \mathrm{g}^{-1}$, it becomes almost stable upto 80th cycle (Coulombic efficiency around 99\%). This decrease in capacity might be attributed to the reduction of the electrolyte and the subsequent SEI formation on the thin film surface as mentioned previously. Once a stable SEI layer is formed on the anode surface, the decay in the capacity disappears and a steady-state regime of the chargedischarge capacity is reached (see figures 6b), eventually.

When the electrochemical performance of the nanostructured $\mathrm{Cu}-\mathrm{Sn}-\mathrm{C}$ thin film is observed (figure $6 \mathrm{c}$ ), the first cycle in Columbic efficiency is around $70 \%$, which then increases to $99.5 \%$ after 20 cycles. The theoretical initial discharge capacity of $\mathrm{Cu}-\mathrm{Sn}-\mathrm{C}$ thin film can be calculated considering the additional capacity coming from the presence of $\mathrm{C}$ (theoretical capacity: $372 \mathrm{mAh} \mathrm{g}^{-1}$ ), resulting in $618.95 \mathrm{mAh} \mathrm{g}^{-1}((991 \times 0.5924)+(372 \times 0.0857)=618.95$ $\left.\mathrm{mAh}^{-1}\right)$ as the first discharge capacity in total. This theoretical value is lower than the value shown in figure 5(c) (900 $\mathrm{mAh} \mathrm{g}^{-1}$ ), which could be also explained, considering the SEI layer formation in the thin film surface (Jung and Lee 2011). The improved cycle retention and the high Columbic efficiency ( $>99 \%$ ) detected after the first cycle can be related to the existence of additional $\mathrm{C}$ in the thin film, leading to a higher electrochemical performance of $450 \mathrm{mAh} \mathrm{g}^{-1}$ upto 80 cycles.

Figure 6(d) displays the comparison of cycle number dependence of the insertion and extraction capacities among all the thin films. All the three thin films have a low first cycle Columbic efficiency $(<80 \%)$. SEI layer formation might be a possible explanation for it. However, other possible series of irreversible processes can also lead to the first cycle irreversible capacity change: (i) the inability of extruded $\mathrm{Cu}$ to re-incorporate into $\mathrm{Sn}$ structure, (ii) the inconsistency in the 'rearrangement' of the electrode structure depending on the carbon presence and (iii) a possible contact loss between the thin film and the current collector due to the volume change (Li et al 2002; Wang et al 2007). The comparison also reveals that even all the three samples are fabricated via GLAD method and have a large surface area to reduce the local current density and decrease polarization, they perform different performances due to their different compositions and indeed their structures and morphologies. As mentioned previously, the porosity in the thin films changes 

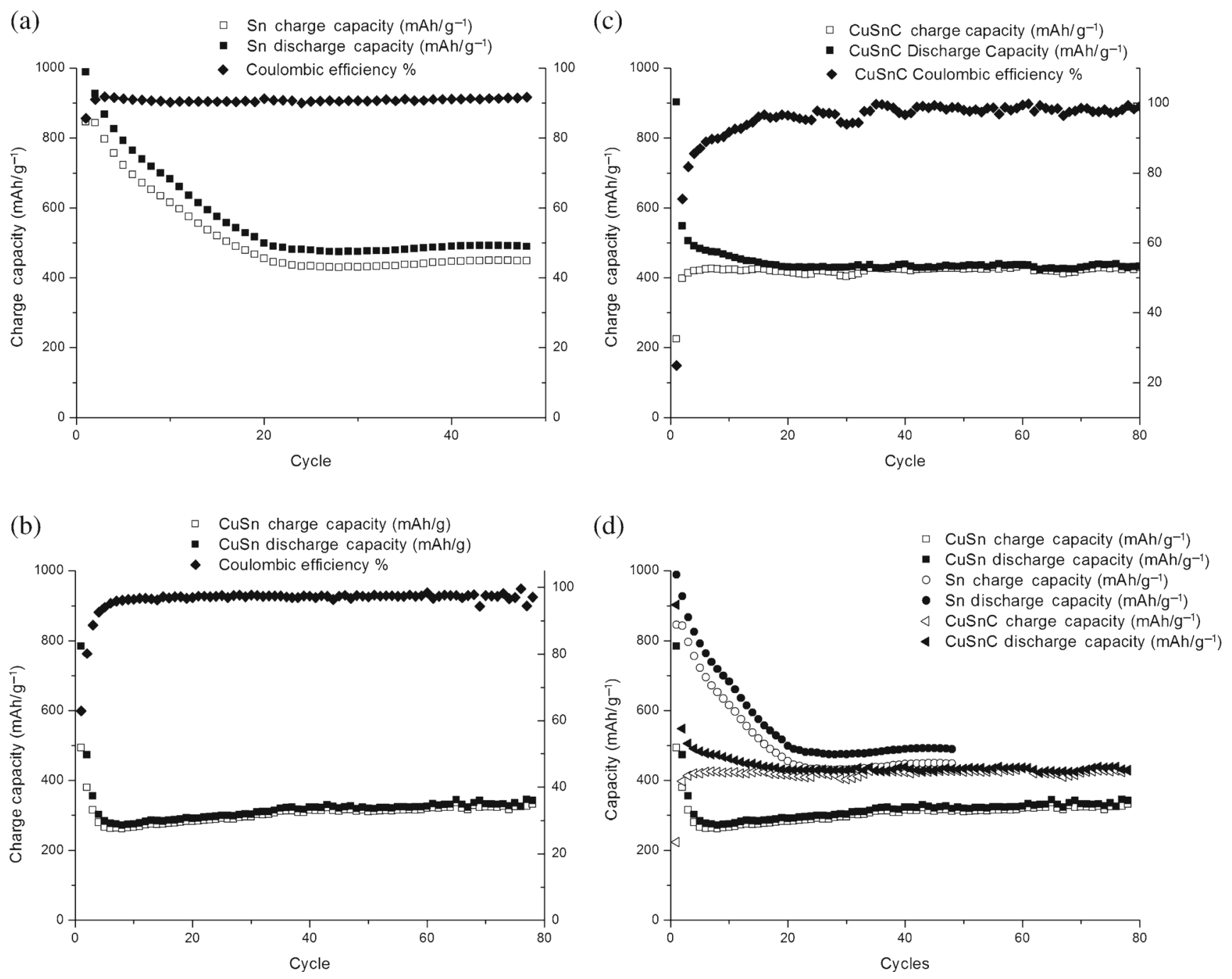

Figure 6. Discharge-charge capacities of the as deposited nanostructured (a) bare $\mathrm{Sn}$, (b) $\mathrm{Cu}-\mathrm{Sn}$, (c) $\mathrm{Cu}-\mathrm{Sn}-\mathrm{C}$ thin films upon cycling and (d) comparison of electrochemical performances of $\mathrm{Sn}, \mathrm{Cu}-\mathrm{Sn}$ and $\mathrm{Cu}-\mathrm{Sn}-\mathrm{C}$ thin film anodes.

depending on their morphology, and the structure depends on the nucleation and growth mechanisms of the evaporated particles. Thus, the $\mathrm{Cu}$ addition which enhances the composite nanorod formation in the thin film, facilitates $\mathrm{Li}^{+}$ movement within the electrode and shortens the $\mathrm{Li}^{+}$diffusion distances. Added to this, the excessive amount of $\mathrm{Cu}$ having a buffering effect improves the tolerance of the thin films against the drastic volume change because of its ductile properties and increases the electrical conductivity of the thin films due to its conductive behavior to promote the charge transferring reactions of the electrode during cycling test (Shin and Liu 2005; Thackeray et al 2005). Figure 6(d) also reveals that the presence of $\mathrm{C}$ augments the Coulombic efficiency of the sample once a stable oxide layer forms on the electrode. This could be explained referring to SEI composition analyses, where the presence of $\mathrm{C}$ in the thin films improves the electrical and mechanical properties of SEI layer, which improves the electrochemical performance of the anode as well (Wang et al 2006).

\section{Conclusions}

In this paper, the oblique angle deposition process is used to produce nanostructured $\mathrm{Sn}, \mathrm{Cu}-\mathrm{Sn}$ and $\mathrm{Cu}-\mathrm{Sn}-\mathrm{C}$ thin films.

The results of this work can be summarized as follows:

(I) GLAD method is a useful method to produce nanostructured Sn-based thin films. The production process may open a new area of research for the development of metal storage electrodes since there is no risk of hazardous handling of flammable, explosive or cancerogenous metal nanoparticles; and no need and limitation of (traditional) binder or conductive additives. We believe that this composite thin film with nanoporosities will have use as potential anode material in lithium battery storage.

(II) To our knowledge, up to now, there is no published work in which a carbon contained nanostructured $\mathrm{Cu}-\mathrm{Sn}$ thin film is produced by using an oblique angle deposition method. 
(III) Pure Sn nanorods have a higher initial anodic capacity of $980 \mathrm{mAh} \mathrm{g}^{-1}$, but the capacity diminishes after 20 cycles due to the morphological changes. When the cycling is continued upto 50th cycles, then it failed.

(IV) A remarkable nanostructured $\mathrm{Cu}-\mathrm{Sn}-\mathrm{C}$ thin film made of small particles with homogeneously distributed porosities is formed by using the GLAD method. Initial discharge capacity is found to be around $900 \mathrm{mAh} \mathrm{g}^{-1}$, then a gradual decrease is noticed upto 20th cycles, then after 20 cycles the capacity becomes fairly constant around $450 \mathrm{mAh} \mathrm{g}^{-1}$ upto 80th cycles.

\section{Acknowledgements}

This work is a part of the research project $110 \mathrm{M} 148$ approved by The Scientific and Technological Research Council of Turkey (TUBITAK). The research grant is gratefully acknowledged.

\section{References}

Belt J R, Ho C D, Motloch C G, Miller T J and Duong T Q 2003 J. Power Sources 123241

Besenhard J O, Komenda P, Paxinos A, Wudy E and Josowicz M 1986 Solid State Ionics 18-19 823

Besenhard J O, Yang J and Winter M 1997 J. Power Sources 6887
Chen C K, Zhang X F and Cui Y 2008 Nano Lett. 8307

Derrien G, Hassoun J, Panero S and Scrosati B 2007 Adv. Mater. 19 2336

Jung H R and Lee W J 2011 J. Electrochem. Soc. 158(A) 644

Kamali A R and Fray D J 2011 Recent Adv. Mater. Sci. 2714

Kawakami S and Asao M 2005 US Patent Application 6949312

Kepler K D, Vaughey J T and Thackeray M M 1999 Electrochem. Solid-State Lett. 2307

Lee K 2007 Synthesis of Si nanowires for an anode material of $\mathrm{Li}$ batteries, Ph.D Thesis (Korea: Pohang University of Science and Technology) p 13

Li H, Shi L H, Wang Q, Chen L Q and Huang X J 2002 Solid State Ionics 148247

Lindsay M J, Wang G X and Li H K 2003 J. Power Sources 11984 Mizutani S and Inoue H 2005 US Patent Application 0208378

Patzig C, Miessler A, Karabacak T and Rauschenbach B 2010 Phys. Status Solidi B 2471310

Shin H-C and Liu M 2005 Adv. Finct. Mater. 15582

Thackeray M M, Vaughey J T and Fransson L M L 2005 JOM 5420

Wang J, Ng S-H, Wexter D, Konstantinov K, Guo Z-P and Liu H-K 2006 Angew. Chem. Int. Ed. 456896

Wang F, Zhao M and Song X 2007 J. Alloys Compd. 439249

Wachtler M, Besenhard J O and Winter M 2001 J. Power Sources 94189

Zhang R, Upreti S and Whittingham M S 2011 J. Electrochem. Soc. 158 A1498 